\title{
A MEMÓRIA E O TESTEMUNHO NA CONSTRUÇÃO NARRATIVA DE COMBATEREMOS A SOMBRA DE LÍDIA JORGE
}

\section{RESUMO}

O presente trabalho tem como objetivo realizar a análise da obra Combateremos a sombra, publicado em 2007, de autoria da escritora portuguesa Lídia Jorge. Buscaremos compreender a função da memória e do testemunho, tanto no que diz respeito à construção narrativa, quanto à análise temática dos personagens. Para tanto, utilizaremos a proposta de Santo Agostinho em Confissões, de Nietzsche em Genealogia da moral, de Paul Ricoeur em A memória, a história, o esquecimento e de Seligmann-Silva em Apresentação da questão: a literatura do trauma e $O$ testemunho: entre a fiç̧ão e o real. O intuito é o de promover uma reflexão acerca do modo como a questão da memória surge no interior do romance e a sua intrínseca relação com o testemunho.

Palavras-chave: Memória, testemunho, Combateremos a sombra, Literatura Portuguesa.
Talita de Barcelos Ramos

Doutoranda em Letras pela FURG talitaramosbarra@hotmail.com

\begin{abstract}
The present work aims to analyze the work Combating the Shadow, published in 2007 by the Portuguese author Lídia Jorge. We will try to understand the function of memory and testimony, both in terms of narrative construction and the thematic analysis of the characters. For this we will use the proposal of Saint Augustine in the Confessions, by Nietzsche in the Genealogy of Morality, by Paul Ricoeur in The Memory, History, and Obligations of Seligmann-Silva Follows Presentation of the Question: The Trauma Literature and between fiction and reality. The aim is to promote a reflection on how the issue of memory emerges within the novel, and its intrinsic relationship with the testimony.
\end{abstract}

Keywords: Memory, testimony, Combating the Shadow, Portuguese Literature.

O romance Combateremos a sombra, publicado em 2007, de autoria da escritora portuguesa Lídia Jorge, inicia com a observação da fragilidade da memória: “Deveríamos rir-nos da fragilidade da memória, ou pelo menos sorrirmos das artimanhas do seu 
esquecimento" (JORGE, 2007, p.11). Com isso, a autora observa que, quando contamos um acontecimento passado, ele de fato não se deu exatamente do modo como rememoramos. A nossa memória costuma recordar apenas fatos do que se passou e não o evento completo de modo detalhado, assim algumas informações acabam sendo suprimidas.

Segundo Paul Ricoeur em A memória, a história, o esquecimento, a memória possui um caráter privado. E, por isso, a minha memória é estritamente singular, ou seja, diz respeito somente a mim. Assim como a memória aborda a ligação da consciência com o passado que a habita, "a memória é passado e esse passado é o de minhas impressões" (RICOEUR, 2007, p.107).

É através deste aspecto de ligação com o passado que a memória garante a continuidade temporal do indivíduo, permitindo retornar do presente vivido até aos acontecimentos da infância. Justamente por possuir um caráter singular, a memória, como observado por Ricouer, permite diversas versões para um mesmo acontecimento, pois cada sujeito vislumbra e define o ocorrido de modo único pela perspectiva de sua memória. Portanto, se buscarmos aproximar um fato das versões fornecidas por aqueles que o presenciaram, veremos que o ocorrido não se deu exatamente daquela forma como foi narrado, como é apontado no romance de Lídia Jorge acerca da história de Osvaldo Campos:

Na verdade, decorridos três anos depois da passagem do Milênio, se nos perguntarem o que sucedeu durante essa noite que então tomamos por memorável, pouco mais do que a figura sideral de um fogo-de-artifício em forma de chuva de estrelas a cair sobre o estuário de um rio nos virá à mente. $\mathrm{E}$, no entanto, a vida não se passou bem assim (JORGE, 2007, p.11). 
A história do romance se inicia com a angústia de Osvaldo Campos, um psicanalista, para terminar com um artigo intitulado "Quanto pesa uma alma". Nos entremeios, sua vida começa a desmoronar, sua mulher Maria Cristina decide separar-se após se envolver com o colega de profissão de Osvaldo, o psicanalista Navarra. Percebe-se que Osvaldo está envolto constantemente no universo de traumas e sonhos de seus pacientes. A vida de Osvaldo começa a ruir na virada do milênio. Sua esposa exige que ele compareça a uma festa que está sendo realizada no "Hotel do Guincho". Osvaldo, após a discussão com Maria Cristina, vai para seu consultório, e se esforça para não atender aos telefonemas de seus pacientes, visando ao encontro com Maria Cristina no hotel.

Contudo, quando Osvaldo está se preparando para ir ao Hotel, ao abrir a porta do consultório, encontra Elísio Passos, jornalista aposentado do Diário de Lisboa. Elísio acreditava haver sido envenenado com "Estramónio" por Salazar. Neste momento, o psicanalista sente uma dificuldade em lembrar da imagem do jornalista, fazendo um esforço de memória para trazer a lembrança, ainda que vaga, de Elísio.

A lembrança e a imagem constituem um ponto crítico da fenomenologia da memória. A imaginação e a memória possuem como traço comum "a presença do ausente", e como traço distintivo o afastamento da realidade que supõem a imaginação, e a realidade anterior que suscita a memória (RICOEUR, 2007, p.61). A lembrança se constitui enquanto imagem, e por isso está imbricada na percepção. Em contrapartida, a imaginação pode envolver seres fictícios, quando não representa o real, mas se afasta dele (RICOEUR, 2007, p.64).

Partimos do pressuposto de que se admita a existência de uma lembrança pura, ainda não formulada em imagens. Logo, é durante o trabalho de recordação que essa lembrança 
pura pode ser convertida em imagens. Se levarmos em consideração a sua virtualidade, o passado só pode ser decifrado como passado quando ele surge em imagens presentes: “Imaginar não é lembrar-se" (RICOEUR, 2007, P.168). Uma lembrança, quando se atualiza tende a se manifestar por uma imagem, mas a relação não é correspondente, e a imagem só me levará para o passado se eu buscá-la no passado (RICOEUR, 2007, p.168). Lembrar-se não é só acolher uma imagem do passado, mas implica buscá-la de alguma forma. O verbo lembrar está relacionado com o substantivo lembrança, e o que o verbo representa é a atividade da memória que é "exercitada” (RICOEUR, 2007, p.71).

Santo Agostinho, em Confissões, também aborda a relação entre a memória e a imagem. A memória possui uma relação com os cinco sentidos, pois as sensações que constituem nossas lembranças nos chegam por algum meio ou "porta", termo esse utilizado por Santo Agostinho. Portanto, a memória se constitui pelo que vimos, ouvimos, cheiramos, tocamos, ou pelo paladar que temos: "tudo isso é acolhido no grande abrigo da memória, em não sei que dobra secreta e inefável, para ser retomado, quando for necessário, e trazido de volta" (SANTO AGOSTINHO, 2017, p.259).

Retomando a narrativa de Lídia Jorge, Osvaldo, apressado para chegar ao hotel, deixa o jornalista em um hospital e segue para o hotel. Ao chegar a seu destino, encontra Maria Cristina de braços dados com Navarra. A partir deste momento, a relação do casal está arruinada. Os dois se divorciam, e ela impõe a divisão de bens a Osvaldo que fica com a casa de praia. Imediatamente o psicanalista vai morar definitivamente em seu consultório. Neste período de dificuldades no casamento, Osvaldo se afasta de seus pacientes e de seus alunos, tentando satisfazer os anseios de Maria Cristina. Contudo, ele posteriormente reflete que 
não o deveria ter feito, pois o tempo acabou agindo na memória de seus pacientes e de seus alunos dificultando seu trabalho:

E no entanto, o dia de regresso tinha corrido difíceis, com os alunos sonolentos pela chuva e desmemoriados pelo intervalo, a levantarem questões despropositadas, e os quatro pacientes da tarde, ainda no rescaldo do fim do ano, ou sob a sensação de abandono provocada pelo adiamento das consultas, a surgirem uns após outros, demasiado instáveis (JORGE, 2007, p.96).

As lembranças se organizam em níveis de sentido. A memória constitui a capacidade de percorrer o tempo em continuidade. É na narrativa que se interligam as lembranças e as memórias. A relação da memória com a orientação do tempo é uma orientação de via dupla, do passado para o presente, de trás para frente (RICOEUR, 2007, p.108). O tempo da memorização não é o mesmo tempo que rege os aspectos da vida, pois essa segue sendo guiada por conjunções datadas, guiadas pelo tempo calendário. A própria fugacidade da vida é medida sobre o "tempo crônico indefinido". O tempo calendário é posto numa sequência escalonada de figurações do tempo que não se restringem ao próprio tempo vivido (RICOEUR, 2007, p.164).

Além disso, é preciso observar a dialética que constitui a relação memória/ esquecimento, pois quanto maior o tempo decorrido maior a possibilidade de que o vivido e experimentado seja soterrado pelas dobras da memória. O esquecimento só é viabilizado graças à memória, uma vez que só posso saber que esqueci algo a medida que me lembro de tê-lo o esquecido: “logo, quando lembro a memória, ela está disponível por si mesma na própria memória; mas, quando lembro o esquecimento, ao mesmo tempo estão à disposição 
a memória e o esquecimento, a memória, pela qual lembro; e o esquecimento, que é o que lembro" (SANTO AGOSTINHO, 2017, p.267).

Todas às vezes que Osvaldo chega ao prédio Goldoni, onde fica seu consultório, encontra uma mulher misteriosa que ele define como: "a rapariga do elevador até estava vestida de anorak vermelho". Osvaldo, após a separação, se volta definitivamente para seus pacientes, anotando detalhes em duas agendas distintas: a agenda da secretária de 2001 e a agenda de bolso, uma pequena Pierre Cardin recebida de seus alunos de mestrado.

Um dos pacientes do psicanalista é o General Ortiz, que possuía um complexo de guerra: "Estão lançados os dados como o senhor bem sabe. Antevejo uma batalha de Lepanto generalizada à escala mundial. Mas eles estão cegos, não vêem nada" (JORGE, 2007, p.65). Outro paciente é Lázaro Catembe, um jardineiro angolano proveniente de Luanda. Ele não consegue visualizar motoristas negros e, assim, se punha a esperar por horas a condução, já que sempre que o motorista era negro ele acreditava que não havia condutor, e que o veículo se movia sozinho.

Lázaro Catembe estava na guerra de Luanda em 1992. Ele estava em um veículo, sentado na frente, quando o condutor foi morto e caiu em seu colo, deixando-o impossibilitado de se mover, visto que estava no meio de corpos: o do motorista e de mais quatro indivíduos. Após narrar o fato para Osvaldo Campos, inúmeras vezes, Catembe consegue curar-se de seu trauma ou ao menos consegue aprender a lidar com ele.

Nietzsche, em Genealogia da moral, aborda a questão da memória e, embora o enfoque do filósofo seja voltado a questões de cunho moral, a indicação feita por ele no seguinte excerto é pertinente: “Grava-se algo a fogo, para que fique na memória: apenas o que não 
cessa de causar dor fica na memória" (NIETZSCHE, 2009, p.46). Ainda que o intuito seja uma abordagem da memória pelo viés da moral, a frase é pertinente. Observa-se que o filósofo oferece uma orientação para pensarmos os motivos que fazem com que indivíduos que participam de eventos traumáticos, como no caso de Catembe, sejam posteriormente assolados pelos horrores que presenciaram. Seguindo a perspectiva nietzschiana, poderíamos considerar essas lembranças como memórias da dor. Para assimilar e enfrentar essa dor, Catembe precisa passar pela linguagem, pois somente após narrar, inúmeras vezes, a Osvaldo o ocorrido, é que o jardineiro desenvolve meios de lidar com seu trauma.

Portanto, percebemos a importância da linguagem no processo. Ao transformar seu trauma em memória declarativa, narrando-a para Osvaldo, Catembe sente-se aliviado em relação ao horror da guerra ao qual presenciou, e o trauma que ele tinha. $\mathrm{O}$ indivíduo que testemunha se relaciona de modo diferenciado com a linguagem, ou seja, segundo Seligmann-Silva, "ele desfaz os lacres da linguagem que tentavam encobrir o 'indizível' que a sustenta" (SILVA, 2003, p.48). A linguagem é o traço, um substituto, imperfeito de uma falta ou uma ausência (SILVA, 2003, p.48).

Recorrendo a Freud, Seligmann-Silva afirma que a experiência traumática consiste naquela que não pode ser totalmente assimilada enquanto ocorre. Logo, o testemunho seria não tanto o relato desses acontecimentos violentos, mas da resistência em compreender esses eventos. A função da linguagem neste contexto é dar limites ao que não recebeu uma forma na sua recepção (SILVA, 2003, p.48).

Em determinado ponto da narrativa, Osvaldo Campos recebe a visita de João Manuel Toscano, inspetor de polícia que comunica ao psicanalista o falecimento de seu paciente 
Elísio Passos exatamente na noite em que Osvaldo o deixara na porta do hospital. O policial pede a Osvaldo que the narre os acontecimentos daquela noite; contudo, o professor Campos parece possuir dificuldade em testemunhar os acontecimentos: "Era difícil de explicar. O que tinha acontecido depois?" (JORGE, 2007, 74).

O testemunho é um processo epistemológico que se inicia na memória declarada, passa para o arquivo e para os documentos e culmina na prova documental. O testemunho possui uso jurídico e histórico. Contudo, é questionável até que ponto o testemunho pode ser confiável. A suspeita se desenvolve a partir da percepção de uma cena vivida, que segue na retenção da lembrança, para partir para a fase declarativa e de reconstituição dos traços do acontecimento (RICOEUR, 2007, p.171). O arquivamento histórico e o depoimento judicial são usos determinados para a prova documental historicamente, e para emissão de sentença no caso do judiciário (RICOEUR, 2007,172). Destacamos também que o indivíduo que testemunha se relaciona de modo diferenciado com a linguagem.

A partir de seu testemunho para a polícia, Osvaldo começa a reconsiderar a possibilidade de seu agora paciente falecido haver dito a verdade. Dos pacientes de Osvaldo, alguns estavam em situação de vulnerabilidade financeira e eram encaminhados ao psicanalista por Junô d' Almeida, assessor do ministro e amigo de Osvaldo. Em contrapartida, outros pacientes eram financeiramente abonados, como Maria London Loureiro.

E é esta personagem que narra para Osvaldo aspectos de sua vida, quando ela tinha apenas seis anos e meio. Maria London conta que estava com seus pais em um navio, quando acordara e percebera que estava sozinha. A criança, desesperada, começou a chorar, atraindo a atenção. Graças a esse episódio, fora descoberto que seu pai, o arquiteto 
London Loureiro, traía a esposa Maria Valentina London, e essa, por sua vez, também o traia. Ambos decidem se separar e o arquiteto propõe que Maria London decida com quem quer ficar. No cais, a menina é forçada a escolher. Ela segue na direção do pai, acreditando que se o alcançasse ambos iriam à direção da mãe. Não é o que acontece. Maria London fica com o pai, enquanto a mãe desaparece.

As lembranças de Maria London demarcam, em alguns momentos, aspectos significativos quanto à memória em relação aos cinco sentidos, como já observamos, e reiteramos segundo Santo Agostinho. O filósofo, ao explorar a temática, afirma que, quando vemos ou ouvimos algo não internalizamos o momento em si, mas uma imagem dele, e o que podemos é apreender por qual sentido corporal essas imagens foram gravadas em nós (SANTO AGOSTINHO, 2007, p.261). Maria London, ao rememorar e narrar para Osvaldo Campos uma visita que ela fez com seu pai a um restaurante que ele iria dar de presente para ela, tem as suas lembranças suscitadas pelo espaço e por tudo que ela pode apreender do seu redor através dos sentidos corporais:

A porta de entrada estava guardada por dois cedros escuros metidos em vasos. As hastes formavam um arco de propósito para se passar por baixo... Entrámos, eu e ele. Lá dentro, as toalhas das mesas eram dum rosa gerbéria. Sobre uma delas, quase malva, o pai cheirava a Aqua di Giò e estudava o cardápio como se fosse matéria definitiva para um exame vestibular, mas a reverencia dos empregados à nossa volta era uma coisa de mais (JORGE, 2007, p.112).

A memória corporal se concentra, sobretudo, em incidentes que exploram a memória secundária, a relembrança, e instiga a narrá-los. Logo, a memória corporal é repleta de lembranças afetadas por diferentes níveis de distanciamento temporal. A transformação da 
memória corporal para a memória dos lugares é garantida por ações como descolar-se e habitar. Imediatamente os momentos lembrados são associados a lugares (RICOEUR, 2007, p.57).

Logo, é neste aspecto que se constitui o que Paul Ricoeur define como "lugares de memória". Esses, por sua vez, funcionam como um auxílio à memória, já que os lugares permanecem como inscrições, enquanto as lembranças sonoras se dissipam com mais facilidade (RICOEUR, 2007, p.58). Ainda sobre os lugares de memória, Paul Ricoeur recorre a Edward Casey para argumentar acerca do sentido de espacialidade. $\mathrm{O}$ ato de habitar constitui para os indivíduos uma relação forte entre a datação e o lugar. Os lugares habitados são memoráveis e, por estarem ligados a eles, a memória declarativa sente a necessidade de descrevê-los. Os deslocamentos, e os distintos lugares por onde passamos servem como reminders aos fatos aí ocorridos (RICOEUR, 2007, p.59).

Maria London, em suas conversas com o professor Campos, revela a ele sonhos com navios atracados no cais, nos quais ele a acompanha em excursões pelas embarcações. Logo, ela Ihe fornece o nome destes navios. Osvaldo fica curioso e começa a investigar a entrada e saída destes navios e descobre que os fatos narrados por Maria London não eram fruto de sua ilusão, mas faziam parte da realidade. Osvaldo fica intrigado com toda a situação e pressiona Maria London, que revela a ele um sistema criminoso que envolvia tráfico de drogas, armas e seres humanos, incluindo lavagem de dinheiro e investimentos em paraísos fiscais, com uma ramificação a partir de Lisboa. Ela também fornece ao psicanalista uma lista com nomes de vinte e um envolvidos no sistema criminoso. 
Ainda ressaltamos que Osvaldo, além de psicanalista, também era professor. Em uma de suas aulas, ele diz aos alunos que toda história narrada comporta certa ficcionalização: "Não posso responder, uma coisa é a experiência clínica em si, a outra é o acto de reproduzi-la. Eu prefiro não matar a invenção que a história de cada um desencadeia, quando contada em voz alta. Como se não a tivesse contado. Compreende?" (JORGE, 2007, p.153). É nesta perspectiva que se insere a questão da sutil fronteira entre a realidade e a ficção. Um sujeito que narra um fato pode ficcionalizar alguns detalhes. $\mathrm{O}$ ato de rememorar, de certo modo, já comporta a ficcionalização da história narrada. A factualidade atestada, o narrador em suposição delimitaria uma fronteira visível entre realidade e ficção. A fenomenologia da memória se deparou desde cedo com o caráter problemático dessa fronteira (RICOEUR, 2007, p.172). Essa relação entre ficção e realidade implica a responsabilidade do autor diante do texto. Os limites entre ficção e realidade não podem ser claramente delimitados (SILVA, 2003, p.379).

No decorrer da narrativa, Osvaldo cruza com a "rapariga do anorak vermelho" diversas vezes e fica, a cada encontro, mais curioso com aquela mulher que ele julga ser "pega do foca" como define. O Foca é José Maria Adolfo, dono do apartamento onde a mulher estava morando. Osvaldo sente-se atraído por ela e, após voltar de um encontro com os irmãos Fiori e decidido a ir até a casa de praia, encontra com a mulher novamente; agora já sabendo seu nome: Rossiana. Ele diz a ela que vai para a casa de praia; ela, então, pede para ir com ele, que aceita o pedido.

Osvaldo e Rossiana de Jesus Inacio partem juntos rumo à casa de praia do psicanalista. Ao chegar ao local, Rossiana e Osvaldo se envolvem amorosamente e ela conta sua história 
para ele. As memórias de vida de Rossiana são suscitadas pela memória musical ligada à cantora Diana Ross: “Osvaldo contou, depois, que ela só tinha começado a falar por causa da lembrança da música" (JORGE, 2007, p.280). Novamente, retorna a influência dos nossos cinco sentidos, na construção da memória. Rossiana tem sua memória despertada pela audição. Ao ouvir a música de Diana Ross, ela se recorda de sua mãe e, a partir daí, narra para Osvaldo sua história de vida.

Ela diz que sua família era natural de um lugar chamado Cuíto-Cuanavale-África Austral. Seu pai era um agrônomo italiano que estava estudando a acidez na terra do Cuíto, sua mãe engravidara e partira com as irmãs, os cunhados, e os sobrinhos para a África do Sul. Todos fugiam da guerra que estava a caminho, menos o avô que se suicidara.

Os sobreviventes de eventos traumáticos, como guerras e catástrofes, e suas gerações posteriores se deparam com a tarefa diária de rememorar a tragédia e enlutar os mortos. Tarefa difícil, pois consiste em deparar-se constantemente com as dores do trauma, o que envolve resistência e, ao mesmo tempo, superação da negação, buscando também um consolo que parece ser inalcançável (SILVA, 2003, p.52).

Esse processo é enfrentado por Rossiana, que está constantemente buscando retomar questões relacionadas com sua origem. Ela chega inclusive planejar um retorno ao lugar de origem de sua família, como se houvesse uma necessidade de retomada do trauma, para enfim alcançar uma superação. Como podemos observar no excerto: "De outra forma ela não teria dito - Vendo bem, eu não passo dum espirro da Guerra de Angola que veio parar ao Solar das Turcas. O que mais posso contar que tenha interesse para alguém?" (JORGE, 2007, p.284). 
Rossiana nasceu em Joanesburgo e, três anos depois, a família foi viver em Lisboa. Após o falecimento da mãe, se volta para a sua paixão: a fotografia. Ela organiza um workshop para os amigos do bairro onde vivia, no qual se inscrevem dez rapazes e cinco moças. $\mathrm{O}$ projeto é intitulado "Tudo que voa". Dentre os inscritos, está um personagem fundamental no desenrolar da história de Rossiana: Cisco. Em seguida, ela vai trabalhar em uma clínica de análises e exames de radiologia como técnica de raio-X. Ao atender um doente proveniente da África, ele disse a ela que conhecia no seu local de trabalho duas pessoas nascidas em Cuíto. Então, Rossiana decide visitar os estaleiros, local de trabalho do homem, e passa a fotografar os trabalhadores imigrantes. Entretanto, seu apartamento é invadido e assaltado, e lhe levam tudo.

No trabalho na clínica, Rossiana presencia a chegada de um brasileiro agarrado ao estômago com muitas dores. O homem acaba falecendo devido a um quilo e duzentos gramas de entorpecentes que trazia no estômago. Ela fica intrigada e decide voltar ao estaleiro para tirar mais fotografias. Ao sair do estaleiro, um homem retira os filmes fotográficos, o celular e os cartões de Rossiana, que reage e diz saber como os trabalhadores são explorados e o papel da clínica na qual ela trabalha. O homem da portaria chama outros dois, que a colocam no carro dela e a seguem até chegar a um determinado local, onde a transferem para um jipe com outros três integrantes, levando-a para uma zona de pinhais.

Quando Rossiana acredita que será morta, um dos homens a desamarra e revela ser o Cisco. Eles dizem a ela que está morta para que possa se livrar da morte. Os homens a levam até o prédio "Goldoni", onde ela deve ficar confinada até que eles consigam um passaporte e passagens para ela ir embora. Depois de conhecer toda a história de Rossiana e de se 
envolver com ela, Osvaldo consegue abrigo para ela com as freiras em Roma. Ela parte com a promessa de que ele irá visitá-la assim que possível. Após as declarações de Maria London e da história de Rossiana, Osvaldo conclui estar diante de um sofisticado sistema criminoso que envolve nomes insuspeitos.

Osvaldo decide denunciar esse sistema criminoso. Para tanto, envia cartas com detalhes para o Presidente, para organizações internacionais e se encontra com jornalistas - inclusive recorre a Junô d'Almeida. De todos eles, Osvaldo recebe o mesmo conselho: para que se afaste e não se intrometa nestes assuntos. Em seguida, passa a organizar a sua viagem a Roma para encontrar Rossiana. Ele faz compras, adquirindo dentre os itens um vestido e um perfume para ela. Depois, Osvaldo leva Lázaro Catembe até sua casa de praia, para que o jardineiro possa cuidar do jardim.

Um tempo depois, Maria London vê Lázaro Catembe parado durante horas em frente ao prédio de Osvaldo e pergunta o que ele está fazendo. O jardineiro responde que está esperando Osvaldo para entregar a chave da casa de praia, mas que ele ainda não descera nem mesmo para ir rumo a sua viagem. Então, à porta do consultório de Osvaldo, se reuniram Maria London, Lucas Azevedo - namorado de Maria London- o guarda, Ana Fausta - secretária de Osvaldo- e Lázaro Catembe. Ana Fausta tinha as chaves e entrou sozinha; em seguida, entraram os outros. As passagens para Itália encontravam-se no mesmo local e a mala de viagem estava aberta. Ao atentarem para as chaves de Osvaldo que estavam com Catembe, notou-se que uma era diferente. Tratava-se da chave do terceiro esquerdo. O grupo se dirige para lá e encontram o corpo de Osvaldo Campos de bruços sobre o sofá. 
Durante a investigação, a polícia pouco descobre, visto a maioria não quer testemunhar. As testemunhas, na maioria pessoas próximas a Osvaldo, se recusam a fixar a imagem do professor Campos, que está morto: "Mas esse seria um momento muito difícil de reconstituir, pois além do Lucas Azevedo, que foi objectivo, todas as outras testemunhas se recusaram a fixar essa imagem do professor" (JORGE, 2007, p.463). Com isso, retorna o cerne da questão entre a relação memória e imagem. A memória é construída sobretudo em imagens.

No entanto, é necessário distinguir a imaginação da imagem: "o que conta é a capacidade de criar imagem, comparações e, sobretudo de evocar o que não pode ser diretamente apresentado e muito menos representado" (SILVA, 2003, p.384). A memória nos fornece a possibilidade de nomear as coisas, mesmo quando estas estão ausentes, pois a imagem delas está disponível em nossa memória: “De fato, nomeio uma pedra, nomeio o sol, quando as próprias coisas não estão presentes aos meus sentidos: sem dúvida, as imagens deles estão disponíveis na memória" (SANTO AGOSTINHO, 2017, p.266).

Além disso, é preciso apontar as contradições que diferentes testemunhos fomentam para uma mesma história. Na narrativa, Catembe e o guarda do prédio de Osvaldo apresentam distintas versões quanto ao posicionamento das pedras encontradas junto ao corpo. Um mesmo episódio, no qual ambos participaram, se desenvolve com duas versões. $E$ mesmo que a diferença no depoimento dos personagens seja mínima, já é o suficiente para observarmos o fato de que diferentes sujeitos possivelmente forneceram narrativas divergentes para uma mesma história: “Catembe disse que só se lembrava de ter dado um pontapé e elas se terem espalhado dentro daquela sala branca. O Securitas disse que as 
encontrara numa disposição perfeita, junto à mesa, e que logo assinalara o facto" (JORGE, 2007, p.469).

O testemunho entra na zona de confronto entre testemunhos concorrentes (RICOEUR, 2007, p.155). É necessário observar que tudo se origina com os testemunhos, apesar da insuficiência de confiabilidade, uma vez que não há nada melhor que o testemunho para assegurar que algo aconteceu a quem alguém se dispõe a atestar pessoalmente. Além disso, às vezes, o confronto de testemunhos é o principal recurso para retomada de acontecimentos (RICOEUR, 2007, p.156). A particularidade do testemunho está no fato de que a afirmação de realidade é inseparável da autodesignação do sujeito que testemunha. Dessa ligação, surge a fórmula do testemunho: "eu estava lá". O que se assegura é a realidade da coisa passada e a presença do narrador nos locais do sucedido (RICOEUR, 2007, p.172).

A autodesignação consiste numa troca que funda uma situação dialogal. É diante de outra pessoa que a testemunha irá alegar a realidade do ocorrido, sendo ela ator ou vítima. Entretanto, no momento do testemunho, assume a posição de um terceiro em relação aos protagonistas da ação. Devido a essa estrutura dialogal do testemunho, ressalta-se de imediato a necessidade de crédito da testemunha. A autenticidade do testemunho só será válida após o eco daquele que o recebe e o aceita, e então o testemunho passa a estar não só autenticado, mas também acreditado. É o credenciamento do discurso que abre prerrogativas para a confiança e a suspeita. A psicologia judiciária evoca toda uma lista de dúvidas em relação ao testemunho, como por exemplo, a má percepção, a má retenção e a má reconstituição (RICOEUR, 2007, p.173). 
Na narrativa de Osvaldo, há uma agenda que poderia desvendar o crime da trama de Lídia Jorge, já que continha muitas anotações. Contudo, a agenda foi pega por Ana Fausta, a qual retira o objeto do consultório antes do isolamento da cena do crime. Fica subentendido pela perspectiva de Ana Fausta, segundo as anotações do professor Campos na agenda de bolso, que o assassino ou o mandante do crime seria London Loureiro, o chefe da organização criminosa que Osvaldo buscava denunciar.

Por conseguinte, Combateremos a sombra é um romance que suscita a questão da memória. Partindo do pressuposto de que toda a literatura de algum modo se fomenta através da memória, pois a narração implica rememoração, o romance de Lídia Jorge, entretanto, não só se utiliza da memória enquanto processo de construção narrativa, mas também reflete acerca destas questões. Como vimos, questiona o caráter de durabilidade da memória, a sua relação com os traumas e até mesmo seu uso na forma de testemunho, visto que aquele que testemunha um fato e se põe a narrá-lo necessita rememorar o mesmo, ou seja, torná-lo memória declarativa. Além disso, o personagem central do romance, Osvaldo, é um psicanalista, portanto inúmeras histórias são rememoradas e narradas para ele em seu consultório. Logo, a memória, no romance analisado, tanto o institui narrativamente quanto o organiza, de forma a ecoar em sua construção textual o conteúdo tratado pela autora Lídia Jorge.

\section{REFERÊNCIAS}

AGOSTINHO, SANTO. Confissões. Tradução do latim e prefácio de Lorenzo Mammi - 1aed. São Paulo: Penguin Classics Companhia das Letras, 2017.

JORGE, Lídia. Combateremos a sombra. Lisboa: Dom Quixote, 2007. 
NIETZSCHE, Friedrich. Genealogia da moral: uma polêmica. Tradução, notas e posfácio Paulo César de Souza. - São Paulo: Companhia das letras, 2009.

RICOEUR, Paul. A memória, a história, o esquecimento. Campinas: SP: Unicamp, 2007.

SELIGMANN - SILVA, Márcio. Apresentação da questão: a literatura do trauma. In:

Seligmann - Silva (org) História, memória, literatura: o testemunho na era das catástrofes. Campinas; SP: Unicamp, 2003. (p.45-58)

SELIGMANN - SILVA, Márcio. 0 testemunho: entre a ficção e o real. In:__ Seligmann - Silva (org) História, memória, literatura: o testemunho na era das catástrofes. Campinas; SP: Unicamp, 2003. (p.375-390)

Artigo recebido em: 25 de maio de 2018. Artigo aprovado em: 11 de agosto de 2018. 